\title{
Serial and large investors in initial coin offerings
}

\author{
Dmitri Boreiko • Dimche Risteski
}

Accepted: 19 January 2020 / Published online: 19 March 2020

(C) The Author(s) 2020

\begin{abstract}
This study is the first to provide systematic evidence regarding investor behaviour in initial coin offerings (ICOs), their investment patterns and their role in the success of campaigns. Using hand-collected data on 472 public token sales over the period of 2013-2017, we advance the ICO literature by demonstrating that some contributors often invest in more than one campaign, and such serial investors contribute earlier. However, they are not more informed and fail to pick betterquality ICOs. Only large serial investors invest more in campaigns that raise more funds, attract more contributors, are more likely to reach their hard caps, and distribute tokens that are listed on crypto exchange. Our findings raise the question of whether regulatory or industry self-regulation agreements on information provision measures are needed to protect smaller retail ICO investors that exhibit naïve reinforcement learning behaviour.
\end{abstract}

Keywords Token sales · Initial coin offerings $\cdot$ Serial investors $\cdot$ Blockchain

JEL classifications $\mathrm{G} 11 \cdot \mathrm{G} 32 \cdot \mathrm{M} 13 \cdot \mathrm{O} 16$

\footnotetext{
D. Boreiko $(\bowtie)$

Faculty of Economics and Management, Free University of Bozen-Bolzano, Bolzano, Italy

e-mail: dmitri.boreiko@unibz.it

D. Risteski

Max Planck Institute for Innovation and Competition, Munich, Germany

e-mail: dimche.risteski@ip.mpg.de
}

\section{Introduction}

Crowdfunding - a new method of funding start-ups through online portals by collecting contributions from many smaller, less-sophisticated investors - has become a valid universal tool to finance projects worldwide, regulated and promoted in many countries (Ordanini et al. 2011; Ahlers et al. 2015; Vismara 2016). Blockchain crowdfunding with ICOs and token sales, as a new form of crowd financing, is now a well-established practice worldwide with start-ups raising a collective of above US\$1b monthly in the first half of 2018. The introduction of bitcoin, subsequent development of more versatile blockchains and slow reaction of regulators have created even more favourable landscape for attracting funds from internationally dispersed investors. Funding start-ups through initial coin offerings (ICOs) or token sales, a relatively new and complex phenomenon, involves organisations issuing transferable and generally very liquid tokens to investors. As a result, in the arc of the last 5 years, ICOs have rapidly grown in number and volume, becoming a valid alternative to $\mathrm{VC}$ funding in blockchain-related industries.

Although token sales very much resemble conventional crowdfunding, the former have more flexible terms, a more international investor base, ${ }^{1}$ and are much larger in all dimensions. Indeed, in token sales funding

\footnotetext{
${ }^{1}$ For example, Airswap (USA) token sale that raised more than $\$ 12$ million in October 2017, has attracted more than 12,000 participants from 135 countries and German start-up Request Network has raised more than $\$ 32$ million from more than 11,000 contributors from 135 countries.
} 
by the crowd is taken to the extreme, our data shows an average of 1600 investors per ICO, with average funds raised of $\$ 9$ million. Conventional crowdfunding is dramatically smaller and much less internationalised. ${ }^{2}$ All this indicates that it is important to understand and learn who invests in token sales and how they do so.

Public Ethereum blockchain data allows us to classify and study the behaviour of ICO investors in a similar manner to crowdfunding research (Ahlers et al. 2015; Vismara 2018). However, there is one exception-while all blockchain data is public, it is still pseudo-anonymous. A public observer can see and trace all transactions of an address which is theoretically associated with an investor. Despite this, public profile or any other private information is hidden. Bitcoin blockchain information, for example, is used by Foley et al. (2019) to study the extent of blockchain's usage in illegal activities. Similarly, inspection of ICO contribution contracts could shed light on the ICO investors' behaviour. Occasional reports by successfully funded firms, showing the time or size distribution of contributions and investors' backgrounds, provide only non-systematic and patchy information on who and how invest in ICOs.

An interesting research question not addressed so far in the crowdfunding and ICO literature involves investor experience and the ability of some investors' groups to invest in more successful ICOs. Given the extreme information uncertainty surrounding young start-ups that raise funds through ICOs and the absence of any regulations regarding mandatory information disclosure, investors face a difficult task in identifying more successful token sales and avoiding future flops or pure frauds. Theoretical models of sequential decisionmaking or of sequential information acquisition suggest that informed investors act earlier and might chose to antiherd or anticipate the actions of later informed investors (Jiang and Verardo 2018). Token sales offer an excellent environment to test these theories.

Moreover, rational learning theories posit that investors learn to improve their strategies through experience. On the other hand, behavioural finance describes many psychological biases that hamper the learning process and accumulated experience causes investors to invest less

\footnotetext{
${ }^{2}$ Vismara (2018) reports the averages of 69 investors and $£ 167,000$ fundraising target of 111 campaigns from Crowdcube, UK; Hornuf and Schwienbacher's (2018) sample of 89 campaigns from 4 German crowdfunding platforms have 293 investors per campaign with an average collected amount of $€ 191,135$; Ahlers et al. (2015) sample of Australian crowdsales has an average of 7 investors per campaign.
}

effectively. Naïve reinforcement learning theory predicts that learning agents overweigh their personal experience. Empirical research found support for both hypotheses. Token sales involve selecting and investing in opaque highly complex projects requiring detailed knowledge of distributed ledger technologies and their applications in various business sectors. As such, ICOs represent an interesting venue to see if investors - or even only some groups of investors - do learn from their investment experience.

This paper is the first to provide systematic evidence of ICO investors' types, their investment patterns and role in campaigns' success. Using self-collect data on 472 token sales, which ran from 2013 to October 2017, we fill the gap in the ICO literature and provide detailed evidence on investment patterns of all contributing addresses to 83 ICO campaigns that accepted funding in bitcoins (BTC) and 272 campaigns that were primarily funded with ether (ETH). The pseudo-anonymous nature of the blockchain data permits us to reconstruct the detailed investment history of each contribution address that is presumably associated with a specific investor. We are able to track the bidding histories of 105,472 individual addresses that sent funds to ICOs accepting BTCs and of 264,584 individual addresses to ICOs accepting ETHs.

Around one quarter of all identified contribution contracts invested in more than one ICO, with an average investment in 3.3 ICOs and a maximum of 115 . Our data shows that around $28 \%$ of the contributors invested in several ICOs and some accounts (192) contributed more than $\$ 1 \mathrm{~m}$ in total. While most contributors are small occasional investors, the rest represents experienced investors who actively participated in token sales or accumulated wealth from other investment activities.

Our paper makes several contributions to the learning and crowdfunding literature. First, this study adds to the literature explicating the role of experience in investment behaviour and, more specifically, explores the investment patterns of frequent (serial) and larger investors in blockchain-leveraged crowdfunding. We believe we are the first to study the distribution of investor contributions and activity across time and the first to link investor activities to campaign-related factors. Second, we test rational learning vs. the naïve reinforced learning hypothesis in a crowdfunding context and reach different conclusions as regards small occasional retail investors' and larger and more experienced peers' behaviour.

Our main findings are as follows. Firstly, we provide some novel summary statistics along various so-far 
neglected dimensions for all ICOs and the ones accepting BTC and ETH separately. Given the bitcoin network architecture ${ }^{3}$ it favours using single unique addresses, and as a result, it is virtually impossible to reconstruct an individual investor's history of contributions. This is very different for the data coming from Ethereum blockchain that favours re-usage of a single address (or wallet) where an investor accumulates funds to be send to ICO addresses and receives bought tokens.

In this study, we demonstrate that there is strong statistical evidence that serial and larger investor groups invest earlier, which can be explained by private information about ICO projects, obtained through learning or higher effort. We hypothesise that serial investors have more experience and are better informed than occasional contributors about the quality of the projects offering tokens for sale. Alternatively, we split the investor universe by the size of the invested funds and hypothesise that larger investors are professionals who have private information and are able to choose the best projects. Using a range of success measures, we test whether serial investors build up the portfolios of more successful ICOs and fail to find any statistical evidence of this. Only large and serial investors manage to pick ICOs that collect more funds, attract more contributors, reach their hard caps, raise more money during the first day of the campaign and list the tokens on online exchanges. We conclude that given extreme information asymmetry, even experienced ICO investors fail in selecting better projects and their portfolios are of average quality.

The rest of the paper is organised as follows. In Sect. 2, we review the academic literature. In Sect. 3, we formulate our research hypotheses about the role of ICO investors, timing of their investment and ability to select better-quality ICOs. Section 4 presents the data set and the econometric methods used. Section 5 discusses the main results. The last section addresses the limitations of the study, outlines potential future research agenda and concludes.

\section{Literature review}

The identity and behaviour of investors play a prominent role in finance (Welch 1992) and the investment patterns and portfolio compositions of renowned

\footnotetext{
$\overline{3}$ https://bitzuma.com/posts/five-ways-to-lose-money-with-bitcoinchange-addresses.
}

investors are closely watched and followed by many smaller investors (Hagstrom 2000). The finance literature usually differentiates between small retail investors and larger institutional ones, which are more informed about the quality of lenders and are assumed to make better investment decisions due to scale, reputation, higher information-processing capabilities and experience (Chen et al. 2018). In initial public offerings, Benveniste and Spindt's (1989) theory of bookbuilding assumes that shares are underpriced as compensation for the information revelations of institutional investors who possess valuable private information (Chemmanur et al. 2010; Boreiko and Lombardo 2011). Similarly, in venture capital (VC) funding, a more experienced $\mathrm{VC}$ firm enhances the chance of a start-up's success (Gompers et al. 2010) and serial business angel (BA) investors select better-performing investment targets (Kelly and Hay 1996; Osnabrugge 1998).

Unlike professional investors in traditional capital markets, in the absence of established intermediaries, crowd investors must rely on information provided by entrepreneurs. This strongly aggravates the issue of information asymmetries and greatly increases the value of the peer investors' activities. Kim and Siva (2019) study how an early investor's experience serves as a credible signal of quality for other crowd investors. Moritz et al. (2015) conduct an exploratory qualitative study and find out that peer effects do play a major role in equity crowdfunding, and that investment size is perceived as an indicator of experience or information advantages. Given the higher digital visibility of investment activities, available at the platform level and mostly in reduced form, several studies look at the dynamics of investor behaviour in equity crowdfunding. Such a unique setting allows for investigating the role of information cascades and the role of public profile investors in equity crowdfunding (Vismara 2018) or funding dynamics and the effect of the participation of large investors (Hornuf and Schwienbacher 2018).

Unlike with crowdfunding literature, academic research on the ICO phenomenon is relatively scarce. Several authors have approached token sales from a theoretical perspective and tried to identify the rationale behind this new fundraising method. Catalini and Gans (2017) rely on economic theory to discuss how blockchain technology eliminates the need for a traditional financial intermediary. Cong et al. (2018) study how tokens facilitate transactions among users in 
decentralised settings and allow them to capitalise on the future growth of promising platforms. $\mathrm{Li}$ and Mann (2018) develop a model that shows how transparent tokens' distribution through an ICO overcomes later coordination failures during platform operation. Chod and Lyandres (2018) show that an ICO can facilitate risk-sharing without dilution of control, while Canidio (2018) studies the interactions induced by ICOs between ex-ante financing and ex-post incentives. Catalini and Gans (2019) illustrate how the ICO mechanism allows entrepreneurs to generate buyer competition for tokens, revealing its true value and facilitating coordination among stakeholders due to network effects.

Earlier empirical studies focused on potential determinants of ICO funding success and post-offering tokens performance in the aftermarket. Adhami et al. (2018) collected very basic data on a sample of ICOs which mostly ran in 2017. Fisch (2019), Amsden and Schweizer (2018), Blaseg (2018) and Cerchiello et al. (2019) use more recent samples and attempt to identify the success factors behind ICOs by looking at the funds raised and token listing status. Adhami and Giudici (2019) study the effect of the governance signals of ICO-backed projects such as token rights, institutional setting and team quality. Howell et al. (2018), Momtaz (2018a, b) and Benedetti and Kostovetsky (2018) instead look at post-ICO performance measures of success, such as trading volume, liquidity, first-day underpricing and long-run returns. Boreiko and Vidusso (2019) focus on the role of intermediaries behind successful token sales. An et al. (2019) test the effects of the disclosure of founder background information and the founding team's collective human capital on ICO outcomes. Drobetz et al. (2019) examine the extent to which the ICO market is driven by investor sentiment, whether crypto-related or linked to the general capital market. Huang et al. (2019) study the geographical distribution of ICOs and show that these take place in countries with developed financial markets and advanced digital technologies.

Fisch et al. (2019) provide the only survey study so far on the characteristics of ICO investors and their motivations for funding blockchain start-ups. The authors show that financial as well as ideological and technological motives are equally important to some investors. Moreover, Fisch et al. (2019) call for combining data on ICO ventures, which is frequently used in recent studies, with data on investors. This is exactly what we do in this paper.

\section{Hypotheses}

\subsection{Private information and timing of investment}

Signalling literature (Akerlof 1970; Spence 1973) posits that online crowdfunding markets that are dominated by less sophisticated investors should display severe adverse selection problem. Increased information asymmetry may be mitigated by credible quality signals from high-quality borrowers (Dranove and Jin 2010). As studied by Block et al. (2018a, b), updates from the founders during the campaign have a significant positive effect on the number of investments and total collected funds. In equity, and other types of crowdfunding, the quality of signals is endorsed by the third party, the platform that advertises and runs the campaign. Such endorsements by superior principals (Moritz et al. 2015) are missing in token sales since there is no intermediary between the lenders and borrowers. Boreiko and Vidusso (2019) document that ICO listing and aggregating websites quickly took this niche and provided general information about ICO and even assigned quality ratings that were not very effective at the end to distinguished good projects from bad or even listed the outright frauds at times.

As a result, as shown by Moritz et al. (2015), crowd investors emphasised the positive effect of prior investments made by formal capital providers such as VCs and BAs, given their experience and that they had 'skin in the game' (Gorton and Pennacchi 1995). In the absence of the third parties' endorsement (Colombo et al. 2019), investors consider the signals by observing the behaviour of the others and learning from them (Welch 1992). Based on the peer-effect model (Bikhchandani et al. 1992), it might lead to information cascades among investors who ignore their private information and follow the wisdom of the crowd (Vismara 2018). Alternatively, Scharfstein and Stein (1990) develop a model of irrational herding that would lead to the similar outcome in aggregate investment patterns.

In token sales, the investors not only observe the aggregate funding amount but can scan the contribution contract and see the quantity and size of previous contribution in real time. Although no public profile is available for an individual contribution address as sometimes is the case in equity crowdfunding (Vismara 2018), the potential investors might differentiate between different investor types. Firstly, the size of the investment might serve as an indicator of the perceived 
degree of professionalism (Moritz et al. 2015). As noted by Hornuf and Schwienbacher (2018), business angels and more sophisticated investors naturally invest larger amounts and so conduct a more thorough due diligence and obtain private information about the start-up. Secondly, the investment history, i.e. prior experience in investing in token sales, might serve as a signal of informational advantage built up through a learningby-doing process.

How do various groups of investors decide on the timing of their investment? The financial theory posits that it is optimal to make an investment decision when information about the target is maximised, i.e. at the end of the contribution period. Landsburg (1999) demonstrated that it is optimal to bid late in eBay auctions. Roth and Ockenfels (2002) suggest that late bidding may also have behavioural causes.

From the other side, most token sales in our sample were run as a first-come, first-served (FCFS) mechanism that entailed investors bidding for a limited number of tokens within the prespecified funding period. Excess demand for tokens and fear of missing out induce earlier participation. ${ }^{4}$ Moreover, substantial investments at the start of the campaign send a signal to other investors who face high uncertainty regarding the project's quality. To motivate earlier investments, the majority of projects displayed the total funds raised by the project in real time and offered substantial price discounts to earlier backers, incentivizing them to invest earlier.

More informed individuals have less incentive to wait and observe the actions of their peers, as they possess private information about the project (Bikhchandani et al. 1992). Theoretical models of sequential decision-making (Avery and Chevalier 1999) or of sequential information acquisition (Hirshleifer et al. 1994) suggest that informed investors act earlier and might choose to antiherd (Jiang and Verardo 2018) or anticipate the actions of later informed investors. We should thus observe that informed investors invest earlier in first-come first-served campaigns with a limited number of tokens on sale (in line with arguments related to equity crowdfunding as described in Hornuf and Schwienbacher (2018)).

\footnotetext{
${ }^{4}$ Many token sales ended much earlier than the contribution period end-date. For example, First Blood project sold all tokens within first two minutes of its 28-days long planned contribution period. BAT sold $\$ 35 \mathrm{~m}$ worth of tokens within its first $30 \mathrm{~s}$ of 30 -day-long planned contribution period.
}

Business angels, venture capitalists and institutional investors represent one such group of investors who regularly invest in various asset classes. Having accumulated capital and investment experience, these investors should be characterised by their larger contributions. We therefore formulate our first hypothesis as follows:

H1. Being more informed about projects quality on average, large investors contribute funds earlier in ICO campaigns

Identifying viable and promising start-ups in blockchain-related industries is a challenging task that requires in-depth knowledge of the sector. Moreover, buying tokens differs greatly from the conventional investment process, and investors must learn how to open and run crypto wallets, buy and sell crypto currencies on online exchanges and be aware of cyber security rules. Such knowledge comes with experience gained from investing in cryptocurrencies and/or from participating in more than one token sale. Frequent (serial) ICO investors differ from occasional ones in the level of information they possess and should not delay their decision to invest and imitate the actions of others. We therefore formulate our second hypothesis as follows:

H2. Being more informed about project quality, serial investors on average contribute funds earlier in ICO campaigns

\subsection{Investor experience and learning}

Even if some groups of investors on average contribute earlier to fundraising campaign, this does not necessarily mean that they generally make better investment decisions. Traditional economics and finance models assume that economic agents learn to make better decisions as they acquire more information with experience (Hilgard 1956; Arrow 1962; Grossman et al. 1977). Such rational learning theories posit that investors learn to improve their strategies through experience. Feng and Seasholes (2005) along with Dhar and Zhu (2006) found that investors with more trading experience made more effective investments. Nicolosi et al. (2009) as well as Seru et al. (2009) demonstrated that individual investors do learn from their trading experiences and improve their performance. 
On the other hand, behavioural finance describes many psychological biases that hamper the learning process, and accumulated experience causes individuals to invest less effectively. Naïve reinforcement learning theory predicts that learning individuals overweight their personal experience (Cross 1973; Camerer and Ho 1999). For example, Kaustia and Knüpfer (2012) demonstrate such a phenomenon in the IPO subscription process. Barber et al. (2010) and Choi et al. (2009) provide similar evidence for stock trading and pension plan contributions.

Is experience equally important in entrepreneurial finance and in crowdfunding? The finance literature demonstrates that funding by more experienced BAs or VCs along with the participation of serial entrepreneurs can enhance the chances of success (Kelly and Hay 1996; Gompers et al. 2006). Kim and Siva (2019) provide similar evidence in cases of experienced crowdfunding investors. Given the absence of thirdparty certification and the decentralisation of the investment process in token sales, we hypothesise that prior experience is even more important to ICO serial investors wishing to make better decisions and select more successful ICOs as their investment targets:

H3. Serial crypto investors on average contribute funds to more successful ICOs

Chiang et al. (2010) study frequent IPO investors and conclude that individual investors do not learn from their experiences, whereas institutional investors do not exhibit naïve reinforcement learning. Our data does not allow us to differentiate between retail and institutional investors; however, similar to Moritz et al. (2015) and Hornuf and Schwienbacher (2018), we hypothesise that larger investors should be associated more with professional or institutional investors that might be able to identify more successful projects. We therefore formulate our next hypothesis as follows:

H4. Large investors on average contribute funds to more successful ICOs

If naïve reinforcement learning theory applies to the ICO fundraising process, we should observe on average that more professional investors should learn more from participating in multiple ICO campaigns (Chiang et al. 2010). The size of the investor should thus mediate the effect of experience of serial investors in selecting more successful ICO campaigns. We therefore posit our last hypothesis as follows:

H5. Only large serial investors on average contribute funds to more successful ICOs

\section{Methods}

\subsection{Sample}

To identify all ICO campaigns, we adopt an operational definition that treats an ICO as an unrestricted crowdfunded fundraising campaign that sells the new proprietary tokens to public investors in exchange for existing cryptocurrencies and fiat money as an option. ${ }^{5}$ Given the absence of a coherent and reliable database, the task of constructing a complete list of true ICOs is not easy. We proceed in the following way. The lists from seven of the largest ICO tracking websites ${ }^{6}$ as of 1 November 2017 were taken and merged, eliminating the double entries, and cancelled or unfinished campaigns. The initial list was manually checked for errors and enlarged by additional ICOs found with textual search for words 'ICO', 'crowdfunding' and 'token sales' in Bitcointalk.org forums. Various missing data were filled in using additional sources such as websites of the ICO companies or their archived versions on archive.org; companies' private blogs or hosted on major blogging servers such as Medium.com, Steemit or Dusil; blockchain forums-Bitcointalk, Bitcoingarden, Reddit, Thewiring and Forebits; social media communication channels-Twitter, Facebook, LinkedIn, Tumblr; GitHub and chat channels as places where developers provided information to the interested parties in a relatively safe and confidential manner-Telegram, Slack, Discord; external news and wire articles.

As a result, the constructed database of 573 deals is a unique rich source of international ICO activity from 2013. We further limit our sample by excluding all private token sales (6 cases) which were not open to general public, ICOs that collected less than \$US 100

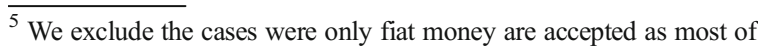
these are usually variations of elaborate frauds or Ponzi schemes not leading to creation of the new cryptocurrency that is traded afterwards. ${ }^{6}$ Smith \& Crown, Tokenmarket, Icobazaar, Coinschedule, Hubcoin, Icodata and Icoprojectrank.
} 
(22 entries), campaigns that stopped interacting with investors during the contribution period and never issued refunds ( 73 entries).

Our final sample consists of 472 ICO campaigns. There is no obvious reason that this sample would bias our inferences regarding the role of experience in timing and effectiveness of investing in ICOs by various groups of contributors in any systematic way. For these ICOs, we tried to identify all valid non-empty bitcoin and ether contribution addresses used by the founders to collect investments. We were able to locate BTC or ETH contribution addresses and download the investment statistics for 83 campaigns out of a total of 237 accepting bitcoins and for 272 campaigns out of 354 accepting ether.

\subsection{Analysis of timing of contributions}

To test the timing of investment, we use OLS model regression with the time of investment of each individual contribution as a dependent variable and the various types of investors as explanatory variables. Specifically, we use the following specification:

$$
\begin{aligned}
\text { Investment_timing }= & \beta_{0}+\beta_{0} \text { Investor }_{\text {type }} \\
& +\alpha_{0} \text { Investor }_{\mathrm{FE}}+\alpha_{1} \mathrm{ICO}_{\mathrm{FE}} \\
& +\varepsilon
\end{aligned}
$$

We used firm and investor fixed-effect dummies to control for multiple contributions to the same ICO contracts and from the same investor to several ICOs. Time of investments was calculated as the relative position of individual contributions within the ICO period according to the following formula: (Contribution timestamp - start of campaign timestamp) / (End of campaign timestamp - start of campaign timestamp).

To identify serial investors, we analysed the summary statistics of all contributions made to bitcoin and ether contracts and marked contracts that sent funds to multiple ICO contribution addresses. We created a Serial Investor dummy that was equal to one if the contribution came from an address recorded in more than two ICOs, and zero otherwise (similar to serial BAs classification adopted by Kelly and Hay 1996 and Osnabrugge 1998).
To identify large investors, we create four investors categories and associated dummies based on the total funds invested in ICOs-Small investors, Big investors, Top $1 \%$ investors and Whales. We classify all contribution addresses as Whales if their total contribution to all ICOs is bigger than $\$$ US1m. We also selected top $1 \%$ of all the investors by invested funds and labelled them as Top 1\% group. Arguably, these two last groups, who are either high-net-worth individuals or professional investors, represent a more experienced investors group in ICOs. The rest of the accounts were classified as either Big or Small investor if their total invested funds were above/below the average US household savings account balance in June 2018 of US $\$ 16,420 .^{7}$ To account for possible interactions of investment frequency and size, we also created interactions dummies of Serial Investor $\mathrm{x}$ Investor size.

\subsection{Analysis of ICO success factors}

To test our last hypothesis that serial and large investors participate in more successful ICOs, we have to define the term 'successful ICO'. Several proxies of campaign success are tested. In crowdfunding, it is usually proxied by a dummy indicating if the projects reach their goals or total number of contributors (Ahlers et al. 2015; Vismara 2018). With token sales, many more measures can be used to represent an ICO's success. We selected the log of total funds raised as the main measure of ICO success. This is an intuitive measure that highlights the investor's interest and belief in the project. Having been used in crowdfunding (Mollick 2014; Ahlers et al. 2015) and VC-funding research (De Clerq and Dimov 2008; Cumming et al. 2005), several scholars (Fisch 2019; Momtaz 2018a) have used this proxy.

To test the robustness of the results, we also use several other measures of ICO success. These include the token being listed afterwards, the total number of contributors and whether the hard cap (an arbitrary maximum financial goal defined by the ICO's launchers) was reached. We used the following specification:

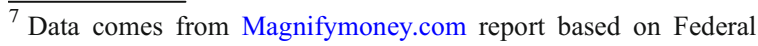
Reserve and the Federal Deposit Insurance Corp. statistics. Retrieved from https://www.magnifymoney.com/blog/news/average-americansavings.
} 


$$
\begin{aligned}
\text { SuccesSProxy }_{=} & \beta_{0}+\beta_{0} \text { Investor }_{\text {participation }} \\
& +\alpha \text { Controls }+\varepsilon
\end{aligned}
$$

We run OLS regressions for logarithms of total funds raised and number of investors' success proxies and logistic regressions for listed status and hardcapreached proxies of success.

To test whether different groups of investors systematically invest in more successful ICOs, we constructed the following explanatory variables of investors' participation. Since virtually all ICOs in the sample obtained contributions from all the investor groups under study, we have decided to measure the investors' interest by the relative proportion of contributions coming from each investor group. For each ICO in the sample, we have aggregated all investments coming from each investors group and normalised them by the total number of contributions and of total funds contributed. These two measures calculated the percentages of total number of investors and total funds that come from serial or four groups of investors by size.

We have selected a wide range of control variables that might influence the ICO success. Our choice was motivated by the accumulated ICO and crowdfunding literature on various types of ICO campaigns' characteristics, governance measures and crypto markets' momentum that might influence ICO success. Appendix Table 7 lists all dependent, explanatory and control variables used in the regressions and provide their brief definitions and data sources.

\section{Results}

\subsection{Descriptive statistics}

Table 1 shows summary statistics for full ICO sample and for the BTC- and ETH-accepting campaigns separately. The data shows that an average ICO in our sample raises \$US9 million with one fifth of all raising less than $\$ U S 100,000$. One sixth of all ICOs have obtained some form of seed financing prior to fundraiser and, in general, founders manage to sell only two fifths of the offered tokens while leaving $14 \%$ of the total for themselves. Less than a third of the campaigns run private presale rounds, closed or restricted for public investors, with $11 \%$ also accepting fiat currencies contributions and almost two thirds of all ICOs offered token price discounts for large or earlier investors. Around $40 \%$ used 'all-or-nothing' model of fundraising used in crowdfunding by defining a minimum sum needed to proceed with the project (min cap). One in five selected a proportional sale model where the price and number of allocated tokens is defined only at the end of the campaign by dividing the total funds raised by the number of offered tokens. Around $6 \%$ of all used an uncapped sale model, where they were ready to accept any amount of money contributed during the campaign period. Around $45 \%$ of all issued tokens are built on Ethereum blockchain with $12 \%$ of all founding teams choosing to run the sale or incorporate the legal entity in jurisdictions that passed ICO-benevolent laws (Singapore, Switzerland and Estonia). The average fundraising campaign is planned to last 32 days, usually ending earlier by 3 days and only two thirds of all issued tokens end up being listed on cryptoexchanges. ${ }^{8}$

The data on BTC- and ETH-run token sales and subsamples of ICOs with identified contribution statistics does not show any selection bias. BTC-run campaigns are clustered more at the start of the sample time period prior to year 2017, when ICOs raised less funds, run more often proportional sales model, were willing to proceed with any amount collected without defined min cap, more aggressively awarded bonus tokens to earlier/ larger investors and developed their own blockchains for tokens. ETH-run campaigns, on the contrary, are clustered at the end of the sample, larger by size and more often marketing the campaign with published whitepaper, offering bonus tokens less often and choosing Ethereum blockchain not only to raise funds but also to build their tokens on it.

We were able to locate and obtain the detailed investment statistics for 83 bitcoin and 272 ether contribution contracts. We have downloaded all BTC contracts' data using API calls to blockchain.com Bitcoin blockchain explorer and used a local copy of the full Ethereum blockchain node to download data for ether contribution contracts. The data includes the contributing address with amount sent in either BTC or ETH and timestamp of the transaction. We further removed zero-value transactions, transactions that had an error status and did not come through, all transactions that took place outside of the

\footnotetext{
${ }^{8}$ We treat a token as listed if it is included in the cryptocurrencies' list of Coinmarketcap.com.
} 
contribution period or were done from the public wallets of intermediaries, such as crypto exchanges. ${ }^{9}$ We also manually checked all transactions bigger than \$US500 , 000 and excluded those that were associated with founders (company moving funds from private sales of tokens or presales) or were representing a smart contract address.

Some general statistics about the distribution of investments by individual contracts and aggregated for each ICO is shown in Table 2. The data clearly illustrates Bitcoin blockchain limitation that precludes any coherent analysis of serial investors' behaviour. In fact, less than $0.6 \%$ (613) of all contributing addresses invested in more than one ICO.

Ethereum blockchain data is different. Around 24.3\% of all contribution contracts invested in more than one ICO $(48,338)$. With this in mind, we have decided to continue with a more detailed analysis of the ICOs subsamples only using available ETH contribution contracts.

Table 3 provides descriptive statistics for the sample composition by investor types and quantity of contributions. The first columns show the investment statistics such as the average number of ICOs invested, total and average contributions and the time span during which the contribution address has the records of transactions to ICOs in our sample. Larger investors on average have a longer ICO investment history recorded on blockchain, On average, an investor in our sample invests in various ICOs over the span of 43 days, with Whales being active over 123 days over the total period under study of 820 days (August 2015-October 2017 for ether-accepting campaigns). Interestingly, the bigger the investor, the earlier she invests (except for Whales). Top $1 \%$ group invests on average at approximately $23 \%$ of the contribution period (in 1-week time from the start) and Small investors at around 10 days from the start. This translates into around 3-day difference between the groups, lending support to Hypothesis 1.

The last four columns of Table 3 look at various measures of ICO campaign success. As expected, larger investors seem to contribute to more successful ICOs (except as measured by the total number of contributors). Surprisingly, serial investors seem on average to invest in less successful ones except as measured by the token rank from marketcoincap.com portal. The higher the rank of the cryptocurrency (the smaller is the

\footnotetext{
${ }^{9}$ For this purpose, we constructed a list of all Ethereum addresses associated with known crypto exchanges (around 100 entries).
}

reported position in the ranking), the larger is the market capitalisation of the token, its liquidity and market interest in the project development.

\subsection{Multivariate analysis}

The results of the regressions on the timing of investments are reported in Table 4. Univariate regressions show that serial and larger investor groups (with an exception of Whales) do invest earlier in the campaign. Considering an average campaign length of 32 days, it translates into a day difference for serial investors and half a day for large contributor groups (Top 1\% and Big). The result is unchanged if we run the multivariate regression with all investor sizes included.

To test the preposition that more experienced investors possess private information and invest earlier, we run the regression with a dummy accounting for serial investors status as well as with interaction dummies of investor size and experience. Surprisingly, although serial investors contribute earlier in the campaign, it is single-investment transactions from Big and Top 1\% groups that have a time advantage. We explain this finding by observing high competition in many firstcome, first-served ICOs in our sample. As a result, serial investors have smaller chances to invest earlier in several campaigns in a regular fashion. Overall, we find clear evidence to support Hypotheses 1 and 2 and may posit that experienced and larger investors, either through learning by investing in crypto assets or by being able to invest on a larger scale do invest earlier in crowdfunding campaigns.

Earlier investment might be an indication of private information about the ICO quality. Whether such an informational advantage is converted into better and more successful investments is tested in Tables 5 and 6. Using an extensive set of controls, we test whether serial and larger investors select ICOs that are more successful as measured by our selected proxies. In Table 5, we report the results for total funds collected and for token listing status in Table 6 .

We fail to find support to the claim that serial investors possess superior information about ICOs and make more informed decisions by selecting more successful ICOs as investment targets. On the contrary, the experienced investors seem to invest less than non-serial ones in all higher-quality token sales. The results hold if we look at the proportion of the total number of investors or at the proportion of total invested funds. Faced with 
Table 1 Summary ICO statistics

\begin{tabular}{|c|c|c|c|c|c|}
\hline & $\begin{array}{l}\text { Total sample } \\
(N=473)\end{array}$ & $\begin{array}{l}\text { Accept BTC } \\
(N=237)\end{array}$ & $\begin{array}{l}\text { Known BTC contract } \\
(N=83)\end{array}$ & $\begin{array}{l}\text { Accept ETH } \\
(N=354)\end{array}$ & $\begin{array}{l}\text { Known ETH contract } \\
(N=272)\end{array}$ \\
\hline Total funds raised, \$US m & 4165.0 & 1817.5 & 392.5 & 3961.3 & 3398.3 \\
\hline $\begin{array}{l}\text { Average funds raised, } \\
\text { \$US m }\end{array}$ & 9.0 & 7.9 & 4.1 & 11.4 & 11.6 \\
\hline $\begin{array}{l}\% \text { collected more } \$ \mathrm{US} \\
50 \mathrm{k}\end{array}$ & 81.8 & 84.4 & 85.6 & 83.3 & 82.7 \\
\hline $\begin{array}{l}\% \text { collected more } \$ \text { US } \\
100 \mathrm{k}\end{array}$ & 77.2 & 78.5 & 77.9 & 80.5 & 79.6 \\
\hline$\%$ with prior $\mathrm{VC}$-backing & 16.7 & 17.3 & 11.5 & 18.6 & 17.0 \\
\hline$\%$ with Whitepaper & 89.2 & 84.0 & 79.8 & 94.4 & 95.6 \\
\hline$\%$ with Github repository & 59.2 & 58.2 & 64.4 & 58.8 & 61.9 \\
\hline$\%$ of total tokens sold & 41.5 & 46.8 & 49.1 & 39.9 & 39.5 \\
\hline $\begin{array}{l}\% \text { tokens retained by } \\
\text { founders }\end{array}$ & 14.4 & 14.8 & 13.8 & 13.9 & 13.7 \\
\hline$\%$ with fiat contributions & 11.0 & 18.6 & 11.5 & 10.2 & 6.8 \\
\hline$\%$ with presale stage & 30.7 & 27.8 & 22.1 & 33.9 & 35.0 \\
\hline$\%$ with bonus offered & 63.6 & 72.2 & 78.8 & 61.6 & 59.9 \\
\hline$\%$ with uncapped sales & 6.1 & 8.0 & 10.6 & 5.6 & 5.4 \\
\hline $\begin{array}{l}\% \text { with proportional } \\
\text { distribution }\end{array}$ & 17.3 & 27.8 & 39.4 & 10.5 & 9.9 \\
\hline$\%$ with defined MC & 41.4 & 33.3 & 29.8 & 44.1 & 45.6 \\
\hline$\%$ with Ethereum token & 63.8 & 41.4 & 29.8 & 81,1 & 87.1 \\
\hline $\begin{array}{l}\% \text { ICO-friendly } \\
\text { jurisdiction }\end{array}$ & 13.7 & 11.4 & 8.7 & 16.7 & 16.0 \\
\hline$\%$ run in year 2017 & 79.7 & 66.2 & 47.1 & 92.4 & 92.5 \\
\hline $\begin{array}{l}\% \text { tokens listed on } \\
\text { exchanges }\end{array}$ & 65.1 & 73.0 & 73.1 & 63.0 & 61.6 \\
\hline$N$ of concurrent ICOs & 69.4 & 41.1 & 22.4 & 87.4 & 93.5 \\
\hline $\begin{array}{l}\text { BTC return } 1 \mathrm{~m} \text { before, } \\
\%\end{array}$ & 17.7 & 15.8 & 11.7 & 19.6 & 20.2 \\
\hline $\begin{array}{l}\text { Average rank on } \\
\text { Coinmarketcap }\end{array}$ & 279 & 325 & 309 & 244 & 235 \\
\hline $\begin{array}{l}\text { ICO campaign planned, } \\
\text { days }\end{array}$ & 32 & 35 & 37 & 29 & 26 \\
\hline $\begin{array}{l}\text { ICO campaign actual, } \\
\text { days }\end{array}$ & 29 & 33 & 37 & 26 & 25 \\
\hline
\end{tabular}

The table shows the selected data for total sample of 472 ICOs and separately for ICOs that accepted either bitcoin or ether as contribution currency and for subsamples with identified contribution contracts. Total/average funds raised are estimated by converting the total/average raised amounts into \$US using the actual-end-of-campaign-dates exchange rates. \% with prior VC-backing shows the proportion of ICOs that obtained VC or BA financing before the campaign. \% with fiat contributions refers to ICOs that accepted contributions not only in cryptocurrencies. \% with presale stage identifies ICOs that prior to public sale run private or restricted sale round for selected investors. $\%$ with bonus offered shows ICOs that featured price discounts for earlier/larger investment. \% with proportional distribution is ICOs that sold their tokens without a fixed price per token. \% of uncapped show a proportion of campaigns run without prespecified hard cap limit. \% with WP is ICOs that published a White Paper before the campaign's start. \% ICO-friendly jurisdiction includes ICOs that have chosen Swiss, Singapore or Estonia jurisdiction for running token sales. Average rank on Coinmarketcap stands for the relative rank of the ICO tokens in the list of all cryptocurrencies as at 31 November 2017

severe information problems, investors that contribute to more than two ICO campaigns seem not to be able to differentiate good from bad projects and their portfolios are equally likely to contain all types of tokens. We therefore reject the Hypothesis 3 that investors with records of contributions to multiple ICOs possess superior information about a project's quality and its future prospects. 
Table 2 ICO investors' participation statistics

\begin{tabular}{|c|c|c|c|c|c|c|}
\hline & Mean & Min & $1 \mathrm{Q}$ & Median & $3 \mathrm{Q}$ & Max \\
\hline \multicolumn{7}{|l|}{ BTC contribution contracts $(N=83)$} \\
\hline$N$ of contributions per ICO & 1565 & 1 & 78 & 392 & 1455 & 15,189 \\
\hline$N$ of investors per ICO & 1280 & 1 & 65 & 337 & 1174 & 15,188 \\
\hline$N$ of ICOs invested in & 1.0 & 1 & 1 & 1 & 1 & 16 \\
\hline Mean contribution, \$US & 893 & 0 & 24 & 119 & 522 & $4,360,543$ \\
\hline Mean contribution per ICO, \$US & 1070 & 0 & 24 & 126 & 589 & $4,360,543$ \\
\hline \multicolumn{7}{|l|}{ ETH contribution contracts $(N=272)$} \\
\hline$N$ of contributions per ICO & 1834 & 1 & 80 & 382 & 1911 & 28,467 \\
\hline$N$ of investors per ICO & 1610 & 1 & 70 & 344 & 1675 & 21,312 \\
\hline$N$ of ICOs invested in & 1.65 & 1 & 1 & 1 & 2 & 115 \\
\hline Mean contribution, \$US & 4172 & 0 & 178 & 598 & 1595 & $10,770,264$ \\
\hline Mean contribution per ICO, \$US & 4735 & 0 & 196 & 701 & 1784 & $10,770,264$ \\
\hline
\end{tabular}

The table shows the distribution statistics for investors' participation in ICOs accepting contributions in BTC (83 ICOs) and in ETH (272 ICOs). Only transactions within the defined public contribution period are counted. $N$ of contributions/ $N$ of investors per ICO identify the total number of transactions/unique contribution addresses recorded on blockchain for a campaign. Nof ICOs invested in shows the statistics on number of ICOs each contribution contract sent funds into. Mean contribution and mean contribution per ICO measure the average size of a single contribution and of total funds invested by each contribution contract into each ICOs

There is some evidence that larger investor groups identify better ICOs, although the results are not robust across all measures of success (Hypothesis 4). We find much stronger results for larger serial investors group, i.e. large serial investors do contribute to ICOs that collect more funds, reach their minimum and hard caps, list the tokens on crypto exchange and attract more investors. This lends statistical support to Hypothesis 5.

To test the robustness of the results, we used several other proxies of ICO success (not reported here) and looked at the proportion of the number of contributions across all ICOs. We also ran the regressions classifying all those that invested in more than one (more than five) ICO as serial investors and those that contributed more than $\$ 50,000$ in total as big investors. Apart from some coefficients turning out insignificant, in general the results hold-serial investors do not seem to possess superior information about projects, although they time the market and invest earlier in the campaign.

\section{Discussion and conclusions}

In this study, we analysed the initial phases of the ICO industry's development from 2013 to 2017 . We collected detailed information on all campaigns in this period, provided a thorough quantitative analysis of the investor behaviour, and laid the foundations for future research in this area. Our main finding was that although serial investors invest earlier on average, they do not possess the skills to select better ICOs. Experience with ICO investing among serial investors leads to naïve reinforcement learning and makes investors select less successful campaigns to invest into. However, larger serial investors do seem to learn from participating in multiple ICO campaigns. We therefore find that the size of the investor (a proxy of their professionalism and general investment experience) does mediate the effect of experience of serial investors in selecting less successful ICO campaigns.

Our study has a number of limitations. Firstly, we lack contribution statistics for some ICOs since they were run with multiple contribution addresses. While the first ICOs in 2013-2014 featured only one contribution address, hacks and security breaches during the ICO campaigns led some projects (133 or $28 \%$ of our sample) to run token sales by setting up an investment portal which required mandatory investor registration and allocated individual contribution addresses. Alternatively, other founders restricted access to the contribution address and only made it public for registered investors during the contribution period. This was aggravated by the recent crackdown by the SEC on token sales deemed to be securities sales in disguise. Many 


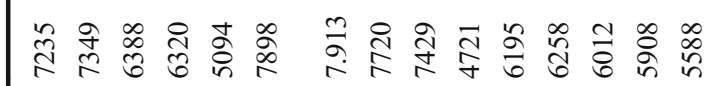

赵卷 卷

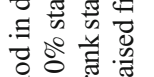

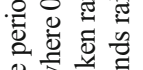

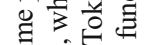

焉

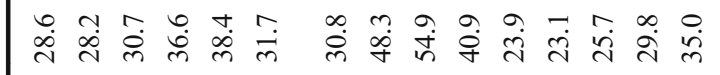

응

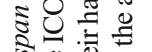

चु

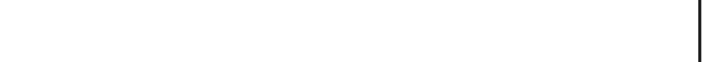

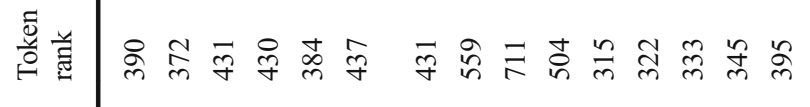

离

(1)

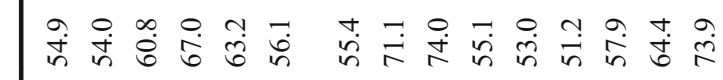
s.

$\ddot{\Xi}$

) <

तो

(a)

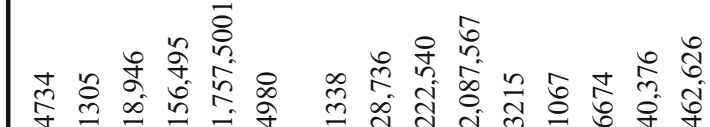

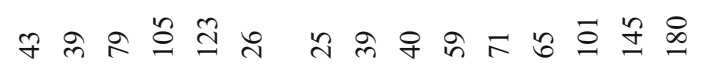

茫焉

要要

ป.

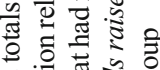

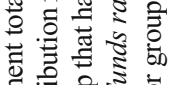

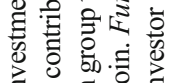

当它芯总手

चै.

늘 =

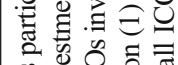

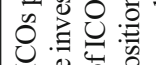

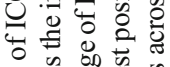

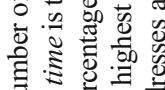

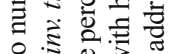

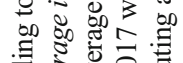

हี

离

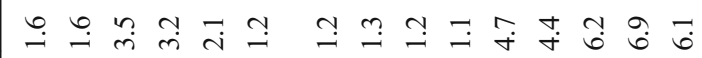

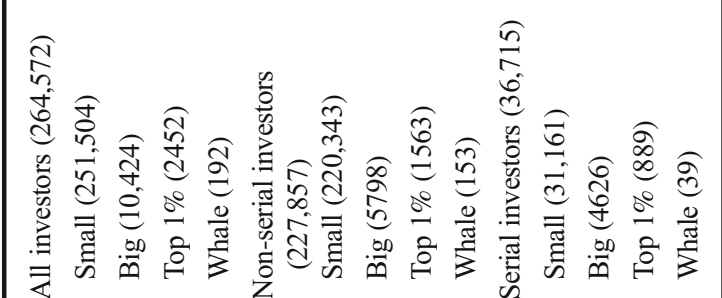

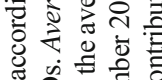

要记

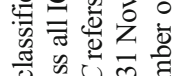

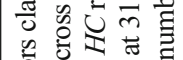

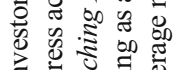

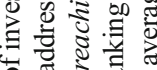

की

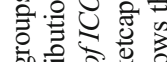

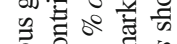

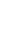

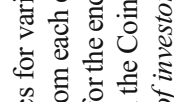

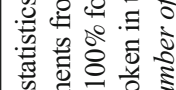

密

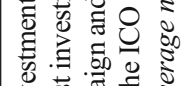

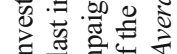

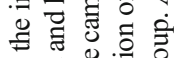

跑导清

进苍各

क

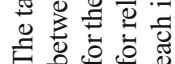


Table 4 Regressions of the timing of investments

\begin{tabular}{|c|c|c|c|c|c|c|c|}
\hline OLS regressions & (1) & (2) & (3) & (4) & (5) & (6) & (7) \\
\hline Serial investor & $-0.04 *$ & & & & & & $-0.04 *$ \\
\hline Small investor & & $0.01 *$ & & & & & \\
\hline Large investor & & & $-0.01 *$ & & & $-0.01 *$ & $-0.04 *$ \\
\hline Top $1 \%$ investor & & & & $-0.02 *$ & & $-0.02 *$ & $-0.04 *$ \\
\hline Whale investor & & & & & 0.01 & 0.00 & \\
\hline Serial $\times$ Big & & & & & & & $0.03 *$ \\
\hline Serial $\times$ Top $1 \%$ & & & & & & & $0.03 *$ \\
\hline Serial $\times$ Whale & & & & & & & -0.01 \\
\hline Firm FE & Yes & Yes & Yes & Yes & Yes & Yes & Yes \\
\hline Investor FE & Yes & Yes & Yes & Yes & Yes & Yes & Yes \\
\hline Constant & Yes & Yes & Yes & Yes & Yes & Yes & Yes \\
\hline Adjusted $R^{2}$ & 0.44 & 0.44 & 0.44 & 0.44 & 0.44 & 0.44 & 0.44 \\
\hline $\operatorname{Prob}(F$-statistics $)$ & 0.00 & 0.00 & 0.00 & 0.00 & 0.00 & 0.00 & 0.00 \\
\hline$N$. of obs. & 498,913 & 498,913 & 498,913 & 498,913 & 498,913 & 498,913 & 498,913 \\
\hline
\end{tabular}

The table shows the regression of the investment timing against various investors' types dummies and their interactions. Firm and investor fixed-effect dummies are used to control for multiple contributions to the same ICO contracts and from the same investor to several ICOs. Time of investments was calculated as the relative position of individual contributions within the ICO period according to the following formula: (Contribution timestamp - start of campaign timestamp) / (End of campaign timestamp - start of campaign timestamp). Investor types are defined in Sect. 4.2 and in Appendix Table 7

* Significance of the respective coefficients at $1 \%$

ICO founders started to delete information about campaigns from their blogs, shutting down set-up token sales portals and closing down ICO communication channels such as Telegram groups. Lastly, some ICOs accumulated collected sums on separate addresses to avoid hacks and thefts, limiting the possibility of identifying the contribution histories of investors. We had to exclude 82 ICOs from our multivariate analysis; however, $t$ tests for differences in means between all ICOs accepting ETH (352) and those with identified contribution statistics (272) were not significant across the whole range of characteristics (last two columns of Table 1).

Another potential limitation of the study is that we cannot completely exclude the possibility that the most sophisticated and experienced investors do use single unique transitory addresses for investing with Ethereum. However, we observed that around a quarter of all investors in our sample re-used a single ETH address and that the average investment size of single-ICO investors is half the size of serial investors $(\$ 5000$ vs. $\$ 11,000)$. Moreover, it is a common practice of token sellers to send the tokens to the contribution address of the investor. A serial investor would thus have to deal with many separate wallets to keep their acquired tokens unless all their investment activity is administered from a single address. Such a practice greatly reduces the network fees associated with deposits and mitigates the risk of investors depositing Ethereum tokens to the wrong address. Lastly, we examined the number of transactions in all Ethereum addresses in March 2019 and noticed that less than a third resembled a transitory address (two credit and two debit transactions at maximum). We therefore conclude that the usage of transitory addresses for ICO investing is rather marginal and does not invalidate our results.

Another issue we investigated was whether our final sample was being contaminated with large transactions coming from organised syndicates pooling resources from individual investors to get better terms or participate in restricted presales of tokens. ${ }^{10}$ We ruled out this possibility for a number of reasons. Firstly, our sample of 472 ICOs has only 72 campaigns with restrictions on minimum investment with an average of \$US210 and median of $\$$ US12, with only two ICOs having a relatively high participation requirement of $\$ \mathrm{US} 5,000$

\footnotetext{
${ }^{10}$ For more information on ICO pools, see Chevalier (2018).
} 
Table 5 ICO total funds raised and serial and large investor participation

\begin{tabular}{|c|c|c|c|c|c|c|}
\hline & (1) & (2) & (3) & (4) & $(5)$ & (6) \\
\hline Serial investor participation, $\%$ of contributions & -0.37 & & & & & \\
\hline Serial investor participation, $\%$ of total funds & & $-1.3 * * *$ & & & & $-2.3 * * *$ \\
\hline Top $1 \%$ investor participation, $\%$ of contributions & & & $4.7 * * *$ & & & \\
\hline Top $1 \%$ investor participation, $\%$ of total funds & & & & $2.7 * * *$ & & \\
\hline Top $1 \% \times$ serial investors participation, $\%$ of total funds & & & & & $1.1^{*}$ & $3.5 * * *$ \\
\hline Average investment & $1.2 * * *$ & $1.2 * * *$ & $1.2 * * *$ & $1.2 * * *$ & $1.2 * * *$ & $1.1^{* * *}$ \\
\hline VC-backed $(\mathrm{Y} / \mathrm{N})$ & $.51 * *$ & $.49 * *$ & $.46^{* *}$ & $.34 *$ & $.50 * *$ & $.44 * *$ \\
\hline Whitepaper (Y/N) & $.65^{*}$ & $.75^{* *}$ & $.66^{*}$ & $.91 * * *$ & $.84 * *$ & $.87 * *$ \\
\hline GitHub (Y/N) & $.57 * * *$ & $.51 * * *$ & $.42 * * *$ & $.41 * * *$ & $.52 * * *$ & $.52 * * *$ \\
\hline Presale $(\mathrm{Y} / \mathrm{N})$ & $.31 * *$ & $.37 * *$ & $.36^{* *}$ & .06 & $.28 * *$ & .19 \\
\hline ICO-friendly law (Y/N) & .14 & .13 & .27 & .19 & .13 & .19 \\
\hline Uncapped sale (Y/N) & .22 & .20 & .13 & .27 & .39 & .15 \\
\hline Bonus tokens $(\mathrm{Y} / \mathrm{N})$ & -.07 & -.03 & -.06 & -.07 & -.03 & -.02 \\
\hline Mincap defined (Y/N) & -.04 & -.12 & -.07 & -.12 & -.17 & -.10 \\
\hline ETH-token (Y/N) & .24 & .26 & .14 & .19 & .24 & .12 \\
\hline Campaign length, days & -.13 & -.13 & -.13 & $-.16^{*}$ & -.14 & $-.15^{*}$ \\
\hline ICO market activity & $-.23 * * *$ & $-.27 * *$ & -.12 & $-.13 *$ & $-.28 * * *$ & $-.16^{* *}$ \\
\hline BTC return, pre-ICO & .27 & -.31 & -.02 & .25 & .34 & .33 \\
\hline ETH return, pre-ICO & .39 & .21 & $.45^{* *}$ & .28 & .20 & .35 \\
\hline Accepting fiat $(\mathrm{Y} / \mathrm{N})$ & $.52 *$ & $.72 * *$ & $.84 * * *$ & $.80 * * *$ & $.74 * *$ & .43 \\
\hline Year dummies & Yes & Yes & Yes & Yes & Yes & Yes \\
\hline Constant & Yes & Yes & Yes & Yes & Yes & Yes \\
\hline Adjusted/McFadden $R^{2}$ & .29 & .24 & .33 & .37 & .23 & .36 \\
\hline$N$. of obs. & 272 & 272 & 272 & 272 & 272 & 272 \\
\hline
\end{tabular}

The table reports the results of the OLS regressions of logarithm of total funds raised in 272 ICO campaigns against serial and large investor participations proxies. Serial (Top 1\%) investor participation, \% of contributions measures a percentage of all investors in each ICO that are serial (top 1\%) investors. Serial (Top 1\%) investor participation, \% of total funds measures a percentage of funds in each ICO contributed by serial (top $1 \%$ ) investors. Top $1 \% \times$ serial investor participation, \% of total funds measures a percentage of funds in each ICO contributed by serial investors who are also in top $1 \%$ of all investors by funds contributed. All control variables are defined in Appendix Table 7

$* * *$ Significance of the respective coefficients at $1 \%$ level

$* *$ Significance of the respective coefficients at $5 \%$ level

*Significance of the respective coefficients at $10 \%$ level

(Moeda and OmiseGo). Moreover, the ICO pools became active only towards the end of $2017,{ }^{11}$ which is outside of our sample period. In addition, we manually checked all contributions above $\$ 500,000$ and excluded those from pooled or founders-associated wallets. We therefore proceed by assuming that all the transactions in our sample are from individual or institutional investors and not from intermediaries.

\footnotetext{
${ }^{11} \mathrm{https} / /$ hackernoon.com/the-ultimate-list-of-ico-pools-in-the-bearmarket-q4-2018-81 ffc4df5a9b.
}

One of the alternative explanations behind the activity of serial investors may be that they do not learn and acquire private information about ICO quality; instead, they simply diversify their crypto investments precisely because they lack information about a particular ICO's quality. ${ }^{12}$ However, if that was the case here, the serial investors would allocate their funds across ICOs in a short time span. Instead, the data (Table 3) shows that frequent investors conduct sequential investments

\footnotetext{
${ }^{12}$ We thank an anonymous referee for raising this point.
} 
Table 6 Listed token and serial and large investor participation

\begin{tabular}{|c|c|c|c|c|c|c|}
\hline & (1) & $(2)$ & (3) & (4) & $(5)$ & (6) \\
\hline Serial investor participation, $\%$ of contributions & $-1.0^{*}$ & & & & & \\
\hline Serial investor participation, $\%$ of total funds & & $-1.8 * *$ & & & & $-2.3 * * *$ \\
\hline Top $1 \%$ investor participation, $\%$ of contributions & & & -1.2 & & & \\
\hline Top $1 \%$ investor participation, $\%$ of total funds & & & & .50 & & \\
\hline Top $1 \% \times$ serial investor participation, $\%$ of total funds & & & & & $2.5^{* *}$ & $5.2 * * *$ \\
\hline VC-backed (Y/N) & $1.0 * *$ & $.99 * *$ & $1.0 * *$ & $.96^{*}$ & $.93 * *$ & .82 \\
\hline Whitepaper (Y/N) & .55 & .60 & 0.7 & 69 & .85 & .86 \\
\hline GitHub (Y/N) & $.87 * * *$ & $.87 * * *$ & $.91 * * *$ & $.85 * * *$ & $.89 * * *$ & $.92 * * *$ \\
\hline Presale $(\mathrm{Y} / \mathrm{N})$ & $1.1 * * *$ & $1.2 * * *$ & $1.1 * * *$ & $1.1 * * *$ & $1.0 * * *$ & $.94 * * *$ \\
\hline ICO-friendly law (Y/N) & $1.8 * * *$ & $1.8 * * *$ & $1.6 * *$ & $1.7 * *$ & $1.6 * * *$ & $1.8^{* * *}$ \\
\hline Uncapped sale (Y/N) & .15 & .04 & .34 & .26 & .32 & .06 \\
\hline Bonus tokens $(\mathrm{Y} / \mathrm{N})$ & .00 & .04 & .04 & .01 & .04 & .01 \\
\hline Mincap defined (Y/N) & .01 & .14 & .00 & .02 & -.60 & -.01 \\
\hline ETH-token $(\mathrm{Y} / \mathrm{N})$ & $1.5 * * *$ & $1.5 * * *$ & $1.5 * * *$ & $1.5 * * *$ & $1.4 * * *$ & $1.4 * * *$ \\
\hline Campaign length, days & -0.3 & -.26 & -.25 & -.25 & -.24 & -.27 \\
\hline ICO market activity & $-.51 * * *$ & $-.49 * * *$ & $-.59 * * *$ & $-.51 * * *$ & $-.51 * * *$ & $-.43 * *$ \\
\hline $\mathrm{BTC}$ return, pre-ICO & $-1.4^{*}$ & $-1.4^{*}$ & -1.2 & -1.3 & -1.2 & -1.3 \\
\hline ETH return, pre-ICO & $.82 *$ & $.85^{*}$ & .74 & $.79 *$ & .72 & .72 \\
\hline Accepting fiat $(\mathrm{Y} / \mathrm{N})$ & 0.4 & -.01 & .24 & .31 & .39 & -.02 \\
\hline Year dummies & Yes & Yes & Yes & Yes & Yes & Yes \\
\hline Constant & Yes & Yes & Yes & Yes & Yes & Yes \\
\hline Adjusted/McFadden $R^{2}$ & .28 & .27 & .24 & .24 & .27 & .27 \\
\hline$N$. of obs. & 272 & 272 & 272 & 272 & 272 & 272 \\
\hline
\end{tabular}

The table reports the results of the logistic regressions of listed token dummy of 272 ICO campaigns against serial and large investor participations proxies. Serial (Top 1\%) investor participation, \% of contributions measures a percentage of all investors in each ICO that are serial (Top 1\%) investors. Serial (Top 1\%) investor participation, \% of total funds measures a percentage of funds in each ICO contributed by serial (Top 1\%) investors. Top $1 \% \times$ serial investor participation, \% of total funds measures a percentage of funds in each ICO contributed by serial investors who are also in top $1 \%$ of all investors by funds contributed. All control variables are defined in Appendix Table 7

$* * *$ Significance of the respective coefficients at $1 \%$ level

**Significance of the respective coefficients at $5 \%$ level

*Significance of the respective coefficients at $10 \%$ level

spread over time (the average investment activity period of serial investors is around 70 days, and twice as long for larger serial investors) although on average there are 90 concurrent ICO campaigns to invest into (Table 1). We believe that this data lends credibility to our original hypothesis of serial investors learning from their experience but failing to select better investment targets due to naïve reinforcement learning.

Our findings raise the question of whether regulatory protections or industry-wide self-regulation measures are needed for retail investors participating in token sales. National regulators so far have either banned ICO activities or have been too slow in laying down clear rules for founders and investors (with some exceptions, such as Switzerland, Singapore and Estonia). Major industry players such as crypto exchanges should probably come forward here and agree to establish industry standards regarding information provision and common rules for entrepreneurs willing to attract funds with token sales. As an alternative, token sales could be marketed and administered by new crypto underwriters. These parties would stake their reputation on particular token sales and conduct due diligence, ensuring higher levels of security and trust from investors. This is precisely what is going on in the industry where crypto exchanges (e.g. Binance 
with its ICO Launchpad) are running what are now called exchange token offerings.

Given such a rich dataset of investor activity, it remains an open research question if ICO contributors treat the actions of serial and larger investors as credible signals of project quality. The exact dynamics have yet to be studied across various types of token sale auctions and the effects of the bonus campaigns on timing and size of investments. Self-compliance and the effects of the legal tools chosen to ensure smooth token sales also represent fascinating topics for further research. Finally, the post-ICO lives of the projects and comparative studies of token sales versus more traditional financing methods, such as VC and private equity, merit special attention. Notwithstanding the negative attitudes of some national regulators, tokenisation and token sales will only develop further which makes it a promising research venue.

Acknowledgements We wish to thank the participants of the SBE Workshop in Lyon, 6th Crowdinvesting Symposium in $\mathrm{Mu}-$ nich, ADEIMF 2019 Summer conference in Turin, 8th ECN Crowdfunding Convention in Brussel, IFZ FinTech Colloquium in Zug-Rotkreuz, Law \& Economics 2nd Vinson Centre Workshop in Buckingham and IFABS 2019 Conference in Medellin for their valuable feedback. We further like to thank Joern Block, Lars Hornuf, Armin Schwienbacher, Silvio Vismara, Andrea Paltrinieri and anonymous referees for their valuable comments and suggestions.

Funding information This work was supported by the Open Access Publishing Fund of the Free University of Bozen-Bolzano.

Table 7 Variable definitions

\begin{tabular}{|c|c|c|}
\hline & Definition & Data source \\
\hline \multicolumn{3}{|l|}{ Dependent variable } \\
\hline Time of investment & $\begin{array}{l}\text { Calculated as the relative position of each individual contribution within } \\
\text { the actual ICO contribution period and ranges from } 0 \text { to } 1\end{array}$ & Ethereum blockchain \\
\hline Total funds raised & $\begin{array}{l}\text { Total funds raised by an ICO and converted into US dollars at the } \\
\text { exchange rate as at the last day of the contribution campaign }\end{array}$ & $\begin{array}{l}\text { Ethereum and Bitcoin } \\
\text { blockchains, companies' } \\
\text { press releases }\end{array}$ \\
\hline Token listed dummy & $\begin{array}{l}\text { Equals to } 1 \text { if the token was listed in the Coinmarketcap.com list of } \\
\text { cryptocurrencies }\end{array}$ & Coinmarketcap.com \\
\hline Number of investors & $\begin{array}{l}\text { Total number of unique contribution addresses that send Ether to the ICO } \\
\text { contract within the actual contribution period }\end{array}$ & Ethereum blockchain \\
\hline Hardcap-reached dumdum & $\begin{array}{l}\text { Equals to } 1 \text { if the total funds contributed reached the maximum target set } \\
\text { by founders }\end{array}$ & Authors' calculations \\
\hline \multicolumn{3}{|l|}{ Independent variable } \\
\hline Serial investor dummy & $\begin{array}{l}\text { Equals to } 1 \text {, if the investor wallet sent funds to more than two ICO } \\
\text { campaigns }\end{array}$ & $\begin{array}{l}\text { Ethereum blockchain and } \\
\text { authors' calculations }\end{array}$ \\
\hline Whale investor dummy & Equals to 1 , if the total funds contributed by the investor reached $\$$ US1m & Authors' calculations \\
\hline Top $1 \%$ investor dummy & Equal to 1 , if the investor is in the top $1 \%$ by total contributed funds. & Authors' calculations \\
\hline Big investor & $\begin{array}{l}\text { Equal to } 1 \text {, if the investor contributed in total more than the average US } \\
\text { household savings account balance in June } 2018 \text { of US } \$ 16,420 \text {. }\end{array}$ & Authors' calculations \\
\hline Small investor & Equal to 1 , if the investor contributed in total less than US\$16,420. & Authors' calculations \\
\hline $\begin{array}{l}\text { Investor group's } \\
\text { participation by number } \\
\text { of investors }\end{array}$ & $\begin{array}{l}\text { Total number of each investor group's contributors (Serial, Whales, Top } \\
1 \%, \text { Big, Small) divided by total number of investors in each ICO. }\end{array}$ & Authors' calculations \\
\hline $\begin{array}{l}\text { Investor group's } \\
\text { participation by funds } \\
\text { contributed }\end{array}$ & $\begin{array}{l}\text { Total value of each investor group's contributions divided by total funds } \\
\text { contributed in each ICO. }\end{array}$ & Authors' calculations \\
\hline \multicolumn{3}{|l|}{ Control variable } \\
\hline VC-backed dummy & $\begin{array}{l}\text { Equals to } 1 \text { if an ICO obtained VC or BA financing before the campaign } \\
\text { or during presale. }\end{array}$ & $\begin{array}{l}\text { Companies' news and web } \\
\text { search }\end{array}$ \\
\hline
\end{tabular}


Table 7 (continued)

\begin{tabular}{|c|c|c|}
\hline & Definition & Data source \\
\hline Average investment & $\begin{array}{l}\text { Logarithm of total funds invested divided by the total number of } \\
\text { contributors per ICO. }\end{array}$ & Ethereum blockchain \\
\hline Whitepaper dummy & Equals to 1 if an ICO published the whitepaper prior to campaign's start. & Companies' websites \\
\hline GitHub dummy & Equals to 1 if the founders published project's code on GitHub. & Github.com \\
\hline ICO-friendly law dummy & $\begin{array}{l}\text { Equals to } 1 \text { if includes ICOs that have chosen Swiss, Singapore or Estonia } \\
\text { jurisdiction for running token sales. }\end{array}$ & Authors' calculations \\
\hline Uncapped sale dummy & Equals to 1 if the token sale was run without an upper limit (i.e. hard cap). & $\begin{array}{l}\text { Companies' news and web } \\
\text { search }\end{array}$ \\
\hline Bonus tokens dummy & Equals to 1 if the founders offered price discounts to earlier investors. & $\begin{array}{l}\text { Companies' news and web } \\
\text { search }\end{array}$ \\
\hline Presale dummy & $\begin{array}{l}\text { Equals to } 1 \text { if the token sale was preceded by smaller one, usually called a } \\
\text { presale. }\end{array}$ & $\begin{array}{l}\text { Companies' news and web } \\
\text { search }\end{array}$ \\
\hline Mincap defined dummy & Equals to 1 if the token sale was run under all-or-nothing model. & $\begin{array}{l}\text { Companies' news and web } \\
\text { search }\end{array}$ \\
\hline ETH-token dummy & Equals to 1 if the offered token was issued on Ethereum blockchain. & $\begin{array}{l}\text { Companies' news and web } \\
\text { search }\end{array}$ \\
\hline Log campaign length, days & Logarithm of the number of days of the planned campaign & Authors' calculations \\
\hline ICO market activity & $\begin{array}{l}\text { Concurrent number of active ICO campaigns run at the start of the token } \\
\text { sale. }\end{array}$ & Authors' calculations \\
\hline BTC return, pre-ICO & One-month return from investing in bitcoin before the token sale start. & Coinmarketcap.com \\
\hline ETH return, pre-ICO & One-month return from investing in ether before the token sale start. & Coinmarketcap.com \\
\hline Accepting fiat dummy & Equals to 1 if the founders accepted contribution in fiat money. & $\begin{array}{l}\text { Companies' news and web } \\
\text { search }\end{array}$ \\
\hline
\end{tabular}

Open Access This article is licensed under a Creative Commons Attribution 4.0 International License, which permits use, sharing, adaptation, distribution and reproduction in any medium or format, as long as you give appropriate credit to the original author(s) and the source, provide a link to the Creative Commons licence, and indicate if changes were made. The images or other third party material in this article are included in the article's Creative Commons licence, unless indicated otherwise in a credit line to the material. If material is not included in the article's Creative Commons licence and your intended use is not permitted by statutory regulation or exceeds the permitted use, you will need to obtain permission directly from the copyright holder. To view a copy of this licence, visit http://creativecommons.org/licenses/by/4.0/.

\section{References}

Adhami, S., \& Giudici. (2019). The impact of governance signals on ICO fundraising success. Journal of Industrial and Business Economics, 46(2), 283-312.

Adhami, S., Giudici, G., \& Martinazzi, S. (2018). Why do businesses go crypto? An empirical analysis of initial coin offerings. Journal of Economics and Business, 100(C), 64-75.

Ahlers, G., Cumming, K. C., Guenther, D., Schweizer, C., \& D. (2015). Equity crowdfunding. Entrepreneurship Theory and Practice, 39(4), 955-980.
Akerlof, G. A. (1970). The market for "lemons": quality uncertainty and the market mechanism. The Quarterly Journal of Economics, 84(3), 488-500.

Amsden, R., \& Schweizer, D. (2018). Are blockchain crowdsales the new 'gold rush'? Success Determinants of Initial Coin Offerings. SSRN Electronic Journal. https://doi.org/10.2139 /ssrn.3163849.

An, J., Duan, T., Hou, W., \& Xu, X. (2019). Initial coin offerings and entrepreneurial finance: the role of founders' characteristics. The Journal of Alternative Investments, 21(4), 26-40.

Arrow, K. (1962). The economic implications of learning by doing. Review of Economic Studies, 29(3), 155-173.

Avery, C. N., \& Chevalier, J. A. (1999). Herding over the career. Economics Letters, 63, 327-333.

Barber, B. M. Odean, T. Strahilevitz, M. (2010). Once burned, twice shy: naive learning, counterfactuals, and the repurchase of stocks previously sold. Unpublished paper, Berkeley: University of California.

Benedetti, H., \& Kostovetsky, L. (2018). Digital Tulips? Returns to investors in initial coin offerings. SSRN Electronic Journal. https://doi.org/10.2139/ssrn.3182169.

Benveniste, L., \& Spindt, P. (1989). How investment bankers determine the offer price and allocation of new issues. Journal of Financial Economics, 24, 343-361.

Bikhchandani, S., Hirshleifer, D., \& Welch, I. (1992). A theory of fads, fashion, custom, and cultural change as information cascades. Journal of Political Economy, 100, 992-1026. 
Blaseg, D. (2018). Dynamics of voluntary disclosure in the unregulated market for initial coin offerings. SSRN Electronic Journal. https://doi.org/10.2139/ssrn.3207641.

Block, J., Hornuf, L., \& Moritz, A. (2018a). Which updates during an equity crowdfunding campaign increase crowd participation? Small Business Economics, 50(1), 3-27.

Block, J. H., Colombo, M. G., Cumming, D. J., \& Vismara, S. (2018b). New players in entrepreneurial finance and why they are there. Small Business Economics, 50(2), 239-250.

Boreiko, D., \& Lombardo, S. (2011). Shares' allocation and claw Back clauses in Italian IPOs. Journal of International Financial Markets, Institutions and Money, 21(1), 121-143.

Boreiko, D., \& Vidusso, G. (2019). New blockchain intermediaries: do ICO rating websites do their job well? Journal of Alternative Investments, 21(4), 67-79.

Camerer, C. F., \& Ho, T. H. (1999). Experience-weighted attraction learning in normal form games. Econometrica, 67, 827874.

Canidio, A. (2018). Financial incentives for open source development: the case of blockchain. MPRA Paper, Germany: University Library of Munich.

Catalini, C. Gans, J. S. (2017). Some simple economics of the blockchain. Rotman School of Management Working Paper no. 2874598; MIT Sloan research paper no. 5191-16.

Catalini, C. Gans, J. (2019). Initial coin offerings and the value of crypto tokens. MIT Sloan research paper no. 5347-18; Rotman School of Management Working Paper no. 3137213.

Cerchiello, P., Tasca, P., \& Toma, A. M. (2019). ICO success drivers: a textual and statistical analysis. The Journal of Alternative Investments., 21(4), 13-25.

Chemmanur, T., Hu, G., \& Huang, J. (2010). The role of institutional investors in initial public offerings. Review of Financial Studies., 23(12), 4496-4540.

Chen, Z., Forsberg, D., \& Gallagher, D. R. (2018). Which institutional investor types are the most informed? Accounting and Finance, 59(S1), 449-480.

Chevalier, L. (2018). ICO pools - what are they? (and how do they differ). Retrieved from https://medium. com/blockinfluence/ico-pools-what-are-they-and-how-dothey-differ-34fld $5 \mathrm{cb} 2573$ on 10/01/19.

Chiang, Y., Qian, Y., \& Sherman, A. E. (2010). Endogenous entry and partial adjustment in IPO auctions: are institutional investors better informed? Review of Financial Studies, 23, $1200-1230$.

Chod, J., \& Lyandres, E. (2018). A theory of ICOs: diversification, agency, and information asymmetry. SSRN Electronic Journal. https://doi.org/10.2139/ssrn.3159528.

Choi, J., Laibson, D., Madrian, B., \& Metrick, A. (2009). Reinforcement learning and savings behavior. Journal of Finance, 64, 2515-2534.

Colombo, M. G., Meoli, M., \& Vismara, S. (2019). Signaling in science-based IPOs: the combined effect of affiliation with prestigious universities, underwriters, and venture capitalists. Journal of Business Venturing, 34(1), 141-177.

Cong, L. Li, Y. Wang, N. (2018). Tokenomics: dynamic adoption and valuation. Columbia business school research paper no. $18-46$.

Cross, J. G. (1973). A stochastic learning model of economic behavior. Quarterly Journal of Economics, 87, 239-266.
Cumming, D., Fleming, G., \& Suchard, J. (2005). Venture capitalist value-added activities, fundraising and drawdowns. Journal of Banking and Finance, 29(2), 295-331.

De Clerq, D., \& Dimov, D. (2008). Internal knowledge development and external knowledge access in venture capital investment performance. Journal of Management Studies, 45(3), 585-612.

Dhar, R., \& Zhu, N. (2006). Up close and personal: investor sophistication and the disposition effect. Management Science, 52(5), 726-740.

Dranove, D., \& Jin, G. Z. (2010). Quality disclosure and certification: theory and practice. Journal of Economic Literature, 48(4), 935-963.

Drobetz, W., Momtaz, P. P., \& Schröder, H. (2019). Investor sentiment and initial coin offerings. Journal of Alternative Investments, 21(4), 41-55.

Feng, L., \& Seasholes, M. S. (2005). Do investor sophistication and trading experience eliminate behavioral biases in financial markets? Review of Finance, 9(3), 305-351.

Fisch, C. (2019). Initial coin offerings ICOs to finance new ventures. Journal of Business Venturing, 34(1), 11-22.

Fisch, C., Masiak, C., Vismara, S., \& Block, J. H. (2019). Motives and profiles of ICO investors. Journal of Business Research. https://doi.org/10.1016/j.jbusres.2019.07.036.

Foley, S., Karlsen, J. R., \& Putniņš, T. J. (2019). Sex, drugs, and bitcoin: How much illegal activity is financed through cryptocurrencies? The Review of Financial Studies 32(5), 1798-1853.

Gompers, P., Kovner, A., Lerner, A., \& Scharfstein, J. (2006). Skill vs. luck in entrepreneurship and venture capital: evidence from serial entrepreneurs. SSRN Electronic Journal. https://doi.org/10.2139/ssrn.933932.

Gompers, P., Kovner, A., Lerner, A., Scharfstein, J., \& D. S. (2010). Performance persistence in entrepreneurship. Journal of Financial Economics, 96, 18-32.

Gorton, G., \& Pennacchi, G. (1995). Banks and loan sales marketing nonmarketable assets. Journal of Monetary Economics, 35(3), 389-411.

Hagstrom, R. G. (2000). The Warren Buffett portfolio: mastering the power of the focus investment strategy. Wiley ISBN: 9780-471-39264-4.

Hilgard, E. R. (1956). Theories of learning (2nd ed.). East Norwalk: Appleton-Century-Crofts.

Hirshleifer, D., Subrahmanyam, A., \& Titman, S. (1994). Security analysis and trading patterns when some investors receive information before others. Journal of Finance, 49, 16651698.

Hornuf, L., \& Schwienbacher, A. (2018). Market mechanisms and funding dynamics in equity crowdfunding. Journal of Corporate Finance, 50, 556-574.

Howell, S. T. Niessner, M. \& Yermack, D. (2018). Initial coin offerings: financing growth with cryptocurrency token sales. National Bureau of economic research paper no. w24774.

Huang, W. Meoli, M. Vismara, S. (2019). The geography of initial coin offerings. Small Business Economics, forthcoming.

Jiang, H., \& Verardo, M. (2018). Does herding behavior reveal skill? An analysis of mutual fund performance. Journal of Finance, 73(5), 2229-2269.

Kaustia, M., \& Knüpfer, S. (2012). Peer performance and stock market entry. Journal of Financial Economics, 104(2), 321338. 
Kelly, P., \& Hay, M. (1996). Serial investors and early stage finance. Journal of Entrepreneurial and Small Business Finance, 5(2), 159-174.

Grossman, S. J., Kihlstrom, R. E., \& Mirman, L. J. (1977). A Bayesian approach to the production of information and learning by doing. Review of Economic Studies, 44(3), 533-547.

Kim, K. Siva, W. (2019). The 'Experts' in the crowd: the role of experienced Investors in a Crowdfunding Market. MIS Quarterly. In press.

Landsburg, S. E. (1999). My way to eBay: an economics professor's strategy for winning online auctions. Slate, Thursday, April 8, 1999.

Li, J. Mann, W. (2018). Initial coin offerings and platform building. SSRN working paper. https://doi.org/10.2139 /ssrn.3088726.

Mollick, E. (2014). The dynamics of crowdfunding: an exploratory study. Journal of Business Venturing, 29(1), 1-16.

Momtaz, P. P. (2018a). Initial coin offerings. SSRN Electronic Journal. https://doi.org/10.2139/ssrn.3166709.

Momtaz, P. P. (2018b). The pricing and performance of initial coin offerings. SSRN Electronic Journal. https://doi.org/10.2139 /ssrn.3169682.

Moritz, A., Block, J., \& Lutz, E. (2015). Investor communication in equity-based crowdfunding: a qualitative-empirical study. Qualitative Research of Financial Markets, 7(3), 309-342.

Nicolosi, G., Peng, L., \& Zhu, N. (2009). Do individual investors learn from their trading experience? Journal of Financial Markets, 12, 317-336.
Ordanini, A., Miceli, L., Pizzetti, M., \& Parasuraman, A. (2011). Crowdfunding: transforming customers into investors through innovative service platforms. Journal of Service Management, 22(4), 443-470.

Osnabrugge, M. V. (1998). Do serial and non-serial investors behave differently?: an empirical and theoretical analysis. Entrepreneurship: Theory and Practice, 22(4), 23-42.

Roth, A., \& Ockenfels, A. (2002). Last-minute bidding and the rules for ending second-Price auctions: evidence from eBay and Amazon auctions on the internet. American Economic Review, 92(4), 1093-1103.

Scharfstein, D., \& Stein, J. (1990). Herd behavior and investment. American Economic Review, 80(3), 465-479.

Seru, A., Shumway, T., \& Stoffman, N. (2009). Learning by trading. Review of Financial Studies, 23, 705-739.

Spence, M. (1973). Job market signalling. The Quarterly Journal of Economics, 87(3), 355-374.

Vismara, S. (2016). Equity retention and social network theory in equity crowdfunding. Small Business Economics, 46, 579590.

Vismara, S. (2018). Information cascades among Investors in Equity Crowdfunding. Entrepreneurship: Theory and Practice, 42(3), 467-497.

Welch, I. (1992). Sequential sales, learning, and cascades. Journal of Finance, 47, 695-732.

Publisher's note Springer Nature remains neutral with regard to jurisdictional claims in published maps and institutional affiliations. 